\title{
Revision of the Plagiolepis schmitzii group with description of $P l$. invadens sp. nov. - a new invasive supercolonial species (Hymenoptera: Formicidae)
}

\author{
Bernhard Seifert ${ }^{1}$ \\ 1 Senckenberg Museum of Natural History Görlitz, Am Museum 1, 02826 Görlitz, Germany \\ http://zoobank.org/A75EEE9F-F43B-4B56-BCF9-14CCB1238C64 \\ Corresponding author: Bernhard Seifert (bernhard.seifert@senckenberg.de)
}

Academic editor: D. Zimmermann • Received 13 April 2020 • Accepted 3 August 2020 • Published 21 September 2020

\begin{abstract}
Using high-resolution stereomicroscopy and exploratory data analyses, a taxonomic revision of the cryptic species close to Plagiolepis schmitzii Forel, 1895, called Pl. schmitzii group, was conducted. Morphology was numerically recorded under highly standardised conditions considering absolute size and 16 shape, pubescence and surface characters. A key to the non-parasitic Westpalaearctic species of the ant genus Plagiolepis Mayr, 1861 is provided which firstly separates, on species group level, the $P l$. pygmaea (Latreille) species group, the $P l$. pallescens Forel species group and the $P l$. schmitzii species group and, finally, on species level, the cryptic species of the latter group. The recognised species of the $P l$. schmitzii species group are $P l$. schmitzii Forel, 1895 (invasive species), Pl. barbara Santschi, 1911, Pl. atlantis Santschi, 1920 and Pl. invadens sp. nov. (invasive species) that is described as new from a supercolony in Germany. Based on morphological arguments, the taxa Pl. barbara var. madeirensis Emery, 1921, Pl. maura polygyna Santschi, 1922 and $P l$. schmitzii var. tingitana Santschi, 1936 are recognised as junior synonyms of $P l$. schmitzii, the taxa Pl. schmitzii crosi Santschi, 1920, Pl. pallescens var. kabyla Santschi, 1920 and Pl. perperamus Salata et al., 2018 as junior synonyms of Pl. atlantis and the taxon Pl. maura Santschi, 1920 as junior synonym of Pl. barbara. A concluding comparative section suggests that pre-adaptations for anthropogenous dispersal and transformation to supercoloniality in introduction areas are apparently common traits in Plagiolepis ants.
\end{abstract}

\section{Key Words}

cryptic species, numeric taxonomy, invasive pest species, supercoloniality

\section{Introduction}

The natural distributional range of the ant genus Plagiolepis Mayr, 1861 includes Africa, Australia and the temperate and tropical zones of Eurasia. Close to 100 available names, attributable to this genus, have been published so far. In the absence of a modern and thorough revision, the genus Plagiolepis is assumed to contain 60 valid species, 20 valid subspecies and 10 valid fossil species (AntWeb 2020). This paper is part of a revision of the independent Westpalaearctic species of the genus conducted by the author through the last four years. The situation in the social parasites (inquilines) of Plagiolepis, with a surprisingly high number of undescribed species, is not considered here. The investigation of independently-living species under highly-standardised conditions revealed the presence of at least 11 good species distributed in the Mediterranean and sub-Mediterranean zoogeographic zones of the Westpalaearctic (this paper and Kirschner et al. in preparation). Morphological discrimination of the many cryptic species in these tiny ants unavoidably requires high-resolution optical systems and highly accurate, reproducible numeric recording of unambiguously defined characters and adequate exploratory and hypothesis-driven data analyses. Several papers dealing with some aspects of Plagiolepis taxonomy of the region were pub- 
lished during the last decades (Radchenko 1989, 1996; Wetterer et al. 2007; Boer 2008; Sharaff et al. 2011). Investigation and analysis methods, quality of equipment and scope of these taxonomic studies were not adequate for the degree of difficulty we encountered here.

A disputable paper on Plagiolepis taxonomy was added very recently: Salata et al. (2018) described Plagiolepis perperamus as new East Mediterranean sister species of Plagiolepis schmitzii Forel, 1895. Detailed comments on this paper are given in the special part below and it was just this particular paper that prompted me to investigate all available types of taxa with a taxonomic position close to Plagiolepis schmitzii. Direct type investigation was possible in nine taxa - six of these turned out as junior synonyms. Junior synonymy of two further taxa appeared most probable by geographic indication and/or inspecting photos in AntWeb (2020). Unfortunately, there was no avenue to assess the status of Plagiolepis barbara var. pyrenaica Emery, 1921. The survey, reported here, resulted in the recognition of four verifiable species in the Plagiolepis schmitzii group and the identification of three senior synonyms of $\mathrm{Pl}$. perperamus Salata et al. (2018).

\section{Material}

Morphometric characters were recorded in a total of 46 samples and 137 worker individuals from Madeira, the Canaries, Europe, North Africa and Asia Minor. Type specimens of nine taxa were investigated. Consideration of males and gynes is not performed here for the following reasons: (a) sexual castes are strongly under-represented in the collections and in many taxa unknown, (b) subjective assessment and tentative morphometrics of the few specimens available suggested that gynes could provide useful characters for species discrimination, but worker-associated nest samples of gynes were not available in just the critical species and (c) the author does not know of a single formicine ant group worldwide where a clear species separation has been testably demonstrated by means of male genitalia.

The material examined is listed in the individual species treatments in the following sequence and format: site, date in the format yyyy.mm.dd, sample number, [latitude in decimal format, longitude in decimal format, altitude]. The accuracy of coordinates is proportional to the number of decimal points and " $x$ " in the sampling date sequence means missing data. In some samples without any direct or derived information on date, the name of the collector is given to allow an approximate conclusion on the period of collection. The abbreviations of depositories are as follows:

DBU Wroclaw Department of Biodiversity and Evolutionary Taxonomy, University of Wrocław, Poland

MCSN Genoa Museo Civico di Storia Naturale Genoa, Italy
MHN Genève

Muséum d'Histoire Naturelle de Genève, Genève, Switzerland

NHM Basel Naturhistorisches Museum, Basel, Switzerland

SMN Görlitz Senckenberg Museum für Naturkunde Görlitz, Görlitz, Germany

\section{Methods}

\section{Equipment and measurement procedures}

All measurements were made on mounted and dried specimens using a pin-holding stage, permitting full rotations around $\mathrm{X}, \mathrm{Y}$ and $\mathrm{Z}$ axes. A Leica high-performance stereomicroscope M165C, equipped with a 2.0 planapochromatic objective (resolution 1050 lines $/ \mathrm{mm}$ ), was used at magnifications of 120-360×. A Schott KL 1500 LCD coldlight source, equipped with two flexible, focally mounted light-cables, providing $30^{\circ}$-inclined light from variable azimuth directions, allowed sufficient illumination over the full magnification range and a clear visualisation of silhouette lines. A Schott KL 2500 LCD cold-light source in combination with a Leica coaxial polarised-light illuminator provided optimum resolution of tiny structures and microsculpture at highest magnifications. Simultaneous or alternative use of the cold-light sources depending upon the required illumination regime was quickly provided by regulating the voltage up and down. A Leica cross-scaled ocular micrometer with 120 graduation marks was used. To avoid the parallax error, its measuring line was constantly kept vertical within the visual field. To avoid rounding errors, all measurements were recorded in $\mu \mathrm{m}$, even for characters for which this precision is impossible. The z-stack photos were made with a Leica Z6 APO photomicroscope, equipped with an objective Planapo 2.0× and a Leica microscope camera DFC420.

\section{The morphometric characters and removal of allometric variance}

Sixteen morphometric characters were investigated in worker ants. In all bilaterally developed characters, arithmetic means of both sides were calculated. The characters are defined as follows:

BPdG - mean distance between the base points of pubescence hairs on dorsal plane of $1^{\text {st }}$ gaster tergite. Usually calculated from the sqPDG and PLG data, providing an approximate solution by the formula BPdG $=\operatorname{sqrt}\left(\mathrm{PLG}^{*} \mathrm{PDG}\right)$. The direct and exact solution is by counting the number of base points $\mathrm{N}$ found within a total area $\mathrm{A}$ with $\mathrm{BPdG}=\operatorname{sqrt}(\mathrm{A} / \mathrm{N})$.

$\mathbf{C L}$ - maximum head (cephalic) length in median line; the head must be carefully tilted at highest magnifications to the position with the true maximum. Excavations of hind vertex and/or clypeus reduce CL. 
CS - cephalic size; the arithmetic mean of CL and CW, used as a less variable indicator of body size.

CW - maximum measurable head (cephalic) width The position of measuring line is defined alone by the maximum and may be across or behind the eyes.

dAN - minimum distance of the inner (centripetal) margins of antennal socket rings which is best measurable in dorsofrontal view [see Fig. 271 in Seifert (2018)].

dTP - distance of the centres of clypeal tentorial pits.

EL - large diameter of the elliptic compound eye measured over all structurally-visible ommatidiae - i.e. also including unpigmented ones in a marginal position.

F2, F3, F4 - median length of $2^{\text {nd }}, 3^{\text {rd }}, 4^{\text {th }}$ funiculus segment in dorsal view. Dorsal view is given when the swivelling plane of $1^{\text {st }}$ funiculus segment is positioned in the visual plane. Take care to really measure median length (the segment's sides often have unequal lengths!) and to recognise the real distal margin of the segments. The latter may have a very thin cuticle, frequently producing a narrow, shining ribbon that seems to be, by optical impression, demarcated from the rest of the segment.

ML - mesosoma length without neck shield (fringe), posterior measuring point: caudalmost point of metapleuron; parallelism of the measuring line to the longitudinal mesosomal axis has to be considered - i.e. in lateral view, the anterior measuring point is found at a lower level of focus.

MW - maximum mesosoma width; this is in worker's pronotal width.

PLG - mean length of at least seven pubescence hairs on dorsal plane of $1^{\text {st }}$ gaster tergite in the area about 30 to $100 \mu \mathrm{m}$ before posterior tergite margin. In the densely pubescent gasters of $\mathrm{Pl}$. schmitzii group species, visualisation of full hair length may be difficult. Take care to provide adequate illumination, vary viewing positions or perform local ablations of pubescence. These clearings expose full hair length at the margins of the adjacent intact pubescence area.

PoOc - postocular distance. Use a cross-scaled ocular micrometer and adjust the head to the measuring position of CL. Caudal measuring point: median occipital margin; frontal measuring point: median head at the level of the posterior eye margin. Note that many heads are asymmetric and average the left and right postocular distance [see Fig. 146 in Seifert (2018)].

PrOc - preocular distance in lateral view; in Plagiolepis, the shortest distance between the anterior eye margin to that point of the genal margin which is in closest proximity to the dorsal condyle of mandibular joint.

SL - maximum straight line scape length (excluding the articular condyle and its neck).

sqPDG - square root of transverse pubescence distance PDG [in $\mu \mathrm{m}$ ] on the dorsomedian part of first gaster tergite about 30 to $100 \mu \mathrm{m}$ before posterior tergite margin. To reduce accidental errors, several countings along differently positioned, transverse measuring lines are averaged until the sum of hairs counted is 50 at least. Exact counting is only possible with clean surfaces, high-resolution stereomicroscopy at magnifications $\geq 280 \times$ and reflection-reduced illumination visualising the full length of hairs. Surface spots with torn-off pubescence are excluded from counting. Measuring procedure: the number of pubescence hairs $\mathbf{n}$ crossing a measuring line of length $\mathbf{L}$ is counted, hairs just touching the line score as 0.5 . Mean PDG is then $\mathbf{L} / \mathbf{n}$.

Removal of allometric variance (RAV) was performed with the procedure described by Seifert (2008). RAV enables a direct comparison of data of related species in tables and improves the performance of principal component analyses considerably. RAV was calculated for the assumption of all individuals having a cephalic size of $\mathrm{CS}=0.45 \mathrm{~mm}$ by overall functions computed as average of specific functions of four species with $>50$ workers per species available. These were Plagiolepis schmitzii, Pl. atlantis, $P l$. taurica and $P l$ occidentalis. The latter name (see Seifert 2018) is not available at present, but will be made available by an upcoming paper of Kirschner et al. (in preparation).

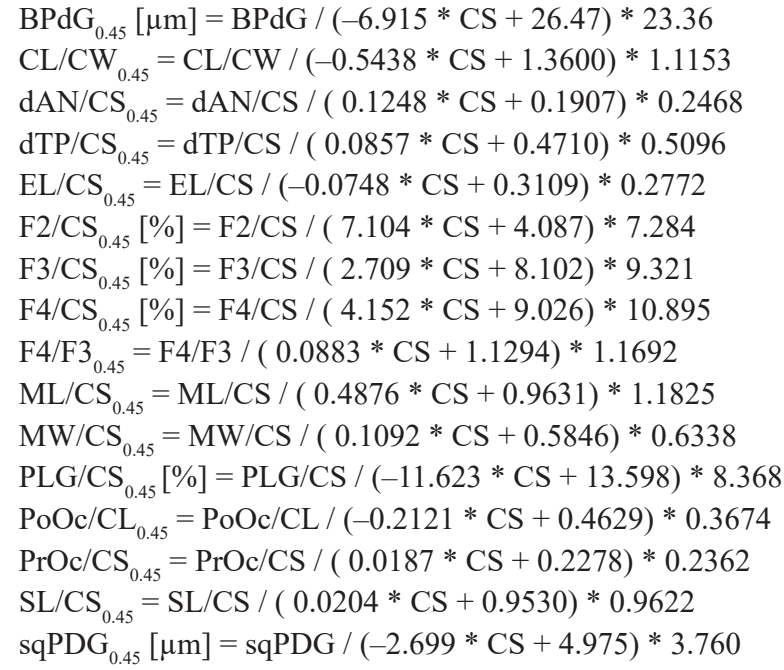

In the species sections, I relinquished presenting verbal descriptions of those morphological characters which may characterise the whole genus or a species group, but are not recognised to have a value for species discrimination. The pictures provided in this paper plus the references to pictures in AntWeb (2020) provide a sufficient overall impression on setae, pubescence and surface characters.

\section{Explorative and supervised data analyses, classification and statistical testing}

Analysing the morphometric data, four forms of exploratory data analyses were run using nest centroids as input data (NC clustering). These were firstly hierarchical NC-Ward clustering, secondly and thirdly, the hierarchical method NC-part.hclust and the iterative vector-quantisation method NC-part.kmeans - both implemented in partitioning algorithms, based on recursive thresholding (for details see Csösz \& Fisher, 2015) and non-metric multidimensional scaling, combined with iterative vec- 
tor-quantisation NC-NMDS-k-means (Seifert et al. 2013). A principal component analysis (PCA) of RAV-corrected data was applied when one of the compared species was present in the data pool with only few specimens, making the application of NC clustering not feasible.

Checking samples with controversial classifications was done by an interaction of $\mathrm{NC}$ clustering and a controlling linear discriminant analysis (LDA) in which these samples were run as wild-cards, following the rationale described in Seifert et al. (2013). The final classification ("final species hypothesis") was established by the LDA in an iterative procedure and there remained no undecided cases, even if their posterior probabilities were close to 0.5 . The decision to recognise a cluster as a valid species was based on the GAGE species concept (Seifert 2020) - here a $<4 \%$ error threshold was applied. LDA, PCA and ANOVA tests were run with the SPSS 16.0 software package.

\section{Results}

\section{The Westpalaearctic species groups of independent Plagiolepis species}

Based on investigation of type specimens and, in some cases, of only their images in AntWeb (2020), the independent species of the genus Plagiolepis of the Westpalaearctic can be subdivided in three major groups:

1 The taxa close to $P$ l. pygmaea Latreille, 1798 which are characterised by the $4^{\text {th }}$ funiculus segment being much longer than the $3^{\text {rd }}$ and the rather widely-spaced basal pits of pubescence hairs on the dorsum of $1^{\text {st }}$ gaster tergite. Data of 20 nest sample means are $1.631 \pm 0.072$ $[1.510,1.784]$ in $\mathrm{F} 4 / \mathrm{F} 3$ and $23.68 \pm 2.99[17.7,28.5] \mu \mathrm{m}$ in BPdG. The mean BPdG translates into 1783 pubescence hairs $/ \mathrm{mm}^{2}$. Without making implications on their potential species status by using here binary names, the described taxa of this group are $\mathrm{Pl}$. pygmaea Latreille, 1798, Pl. obscuriscapa Santschi, 1922 and Pl. karawajewi Radchenko, 1989.

2 the Plagiolepis pallescens group which is characterised by widely-spaced basal pits of pubescence hairs on the dorsum of $1^{\text {st }}$ gaster tergite (Fig. 1a) and the $4^{\text {th }}$ funiculus segment not being much longer than the $3^{\text {rd }}$. Data of 113 nest sample means are $1.160 \pm 0.046$ [1.041, 1.292] in F4/F3 and $30.23 \pm 1.73$ [24.1, 34.2] $\mu \mathrm{m}$ in BPdG. The mean BPdG translates into 1099 pubescence hairs $/ \mathrm{mm}^{2}$. Without making implications here on their potential species status by use of binary names, the described taxa of this complex are $P l$. pallescens Forel, 1889, Pl. minu Forel, 1911, Pl. taurica Santschi, 1920, Pl. sordida Santschi, 1920, Pl. ancyrensis Santschi, 1920, Pl. vindobonensis Lomnicki, 1925, Pl. compressa Radchenko, 1996, Pl. dlusskyi Radchenko, 1996, Pl. calva Radchenko, 1996 and $P l$. sp. OCCIDENTALIS - an undescribed species (name not available at present, Seifert 2018).

3 the Plagiolepis schmitzii group which is characterised by narrowly-spaced basal pits of pubescence hairs on the dorsum of $1^{\text {st }}$ gaster tergite (resulting in a dense pubescence, Fig. 1b) and the $4^{\text {th }}$ funiculus segment not being much longer than the $3^{\text {rd }}$. Data of 46 nest sample means are $1.199 \pm 0.052[1.106,1.362]$ in F4/F3 and $16.27 \pm 1.59[13.4,20.2] \mu \mathrm{m}$ in BPdG. The mean BPdG translates into 3778 pubescence hairs $/ \mathrm{mm}^{2}$. According to the data currently available, this group contains four species: Pl. schmitzii Forel, 1895, Pl. barbara Santschi, 1911, Pl. atlantis Santschi, 1920 and $P l$. invadens sp. nov.

\section{Key to species groups of Plagiolepis and the species of the Pl. schmitzii group}

Note: This key does not consider the parasitic species (inquilines) of the genus which contain a surprisingly high number of undescribed species and are frequently so tiny in size and so weakly sclerotised that traditional forms of ant preparation appear inadequate.

la $4^{\text {th }}$ funiculus segment much longer than $3^{\text {rd }} ; F 4 / F 3>1.44$ [error $0 \%$ in 20 nest means. ..................PI. pygmaea group

$1 \mathrm{~b} \quad 4^{\text {th }}$ funiculus segment only moderately longer than $3^{\text {rd }} ; \mathrm{F} 4 / F 3<1.44$ [error $0 \%$ in 159 sample means] $\ldots \ldots \ldots \ldots \ldots \ldots \ldots . . . . . . . .2$

2a Dorsum of $1^{\text {st }}$ gaster tergite with widely-spaced pits of pubescence hairs and dilute pubescence cover; BPdG $>22 \mu \mathrm{m}$, sqPDG $>3.70$ [error $0 \%$ in 113 sample means]. ............................................................... pallescens group

$2 \mathrm{~b}$ Dorsum of $1^{\text {st }}$ gaster tergite with densely-spaced pits of pubescence hairs and dense pubescence cover; $B P d G<22 \mu \mathrm{m}$, sqPDG $<3.70$ [error 0\% in 46 sample means]; Pl. schmitzii group ......................................................... 3

3a $3^{\text {rd }}$ funiculus segment short; with measurements in $\mathrm{mm}$, discriminant $355^{*} \mathrm{~F} 3-35.54{ }^{*} \mathrm{CW}+1.879<0$. Only known from

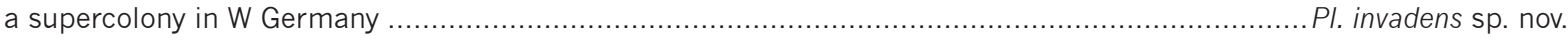

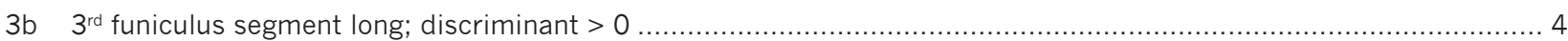

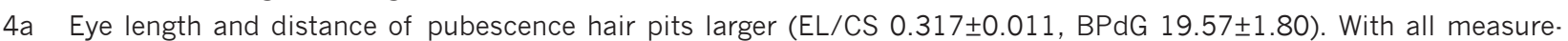
ments in mm, sample means of discriminant $164.75^{*} \mathrm{EL}-42.944 * \mathrm{SL}+0.080^{*} \mathrm{PoOc}-1.224>2.3$ [error 0\% in 3 sample means]. Morocco east to Tunisia

Pl. barbara

$4 \mathrm{~b}$ Eye length and distance of pubescence hair pits smaller (EL/CS 0.274 \pm 0.16 , BPdG 16.18 \pm 1.72 ). Sample means of

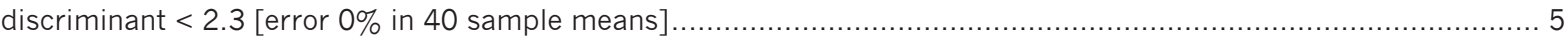

5 a With all measurements in $\mathrm{mm}$, discriminant $48.98^{*} \mathrm{CL}+72.21 * \mathrm{PoOc}-65.80 * \mathrm{SL}-171.2 * \mathrm{~F} 4+173.5^{*} \mathrm{PLG}+35.42 * \mathrm{MW}-12.79$ $<0$ [error $0 \%$ in 64 individuals]. 


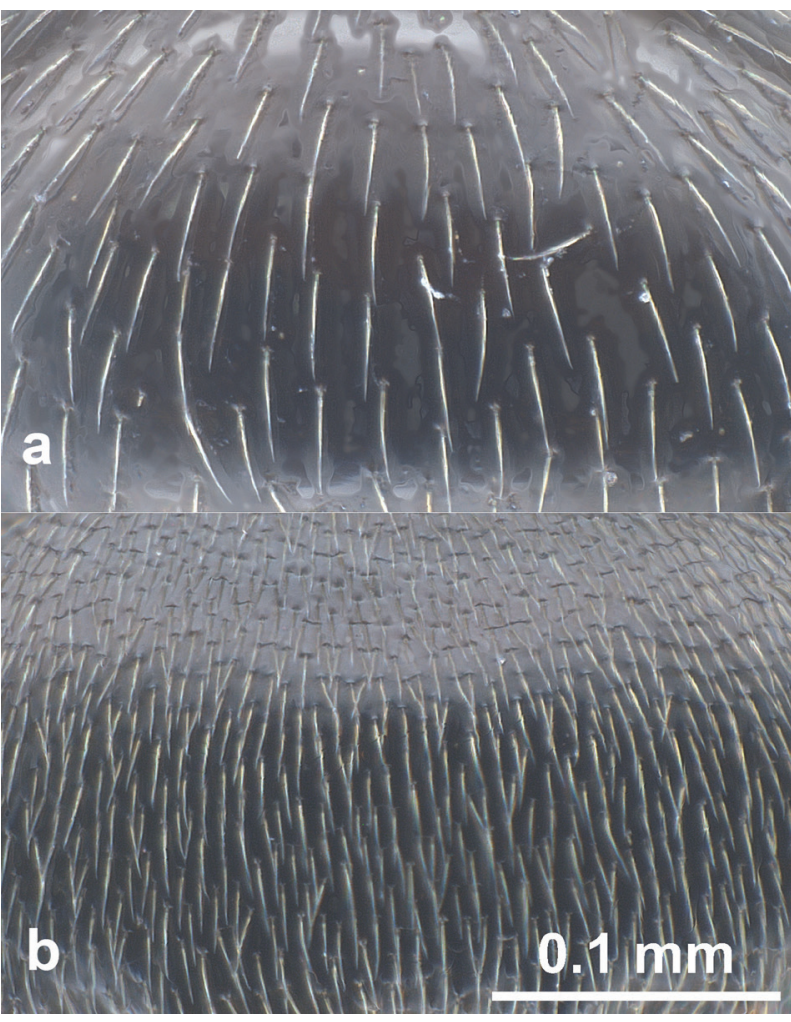

Figure 1. Surface of posterior part of $1^{\text {st }}$ gaster tergite of a worker of Plagiolepis taurica (a) and Pl. schmitzii (b).

\section{Treatment by species}

\section{Plagiolepis schmitzii Forel, 1895}

Plagiolepis pygmaea var. schmitzii Forel, 1895 Published type locality: "Serra d'Agua, Madeira (Seminardirektor P. E. Schmitz)" [32.727 N, $17.027^{\circ} \mathrm{W}, 347 \mathrm{~m}$ alt.]. Nine paratype workers were investigated from MHN Genève collected by Schmitz in at least three localities in Madeira. Amongst these were workers pictured in AntWeb (2020), labelled "Pl. pygmaea Latr. v. schmitzii For. Garajau Madeira Schmitz 3, 5-9", “ANTWEB CASENT0909859". All investigated specimens do not carry a label pointing to Serra d'Agua. I also investigated the lectotype gyne labelled "Pl. pygmaea Latr. v. schmitzii For. Madeira (Schmitz)", “ANTWEB CASENT0909858”, "LECTOTYPE (upper) Plagiolepis pygmaea var. schmitzi Forel, 1895 desig. Wetterer \& Espadaler”.

Plagiolepis barbara var. canariensis Santschi, 1920 [syn. schmitzii] Described from Tenerife: La Laguna, Bejano and Esperanze. No type specimens or figures of this taxon were available and the descriptive statements of Santschi are useless. A junior synonymy with Pl. schmitzii appears probable for zoogeographic reasons.

Plagiolepis barbara var. madeirensis Emery, 1921 [syn. schmitzii] Identification by evaluation of photos of a type worker in AntWeb (2020) labelled "Pl. barbara var. madeirensis Em.”, "SYNTYPUS Plagiolepis barbara var. madeirensis Emery, 1921", "Funchal Madeira De Guerne", “ANTWEB CASENT0905140”.

Plagiolepis maura polygyna Santschi, 1922 [syn. schmitzii] Four type workers were investigated from NHM Basel labelled "Tunisie, Cheri Chera 27 III 21 Santschi”.

Plagiolepis schmitzii var. tingitana Santschi, 1936 [syn. schmitzii] Santschi published as collecting sites "Tanger w. (type) et Volubilis w. (Alluaud)". Four type workers were investigated from NHM Basel labelled "Tanger Ch. Alluaud".
Material examined. A total of 21 samples with 64 workers were subject to morphometric investigation.

Algeria: Mascara, $1926\left[35.398^{\circ} \mathrm{N}, 0.138^{\circ} \mathrm{E}, 594 \mathrm{~m}\right.$ alt.]. England: Isle of Wight: Bonchurch, 2007.06.21 $\left[50.59^{\circ} \mathrm{N}, 1.19^{\circ} \mathrm{W}, 3 \mathrm{~m}\right.$ alt.]. Germany: Schkeuditz, $2019.02 .11\left[51.392^{\circ} \mathrm{N}, 12.204^{\circ} \mathrm{E}, 104 \mathrm{~m}\right.$ alt.]; Schriesheim, 2017.05 [49.470 ${ }^{\circ} \mathrm{N}, 8.46^{\circ} \mathrm{E}, 118 \mathrm{~m}$ alt.]; Seligenstadt, 2009.04 [50.045 $\mathrm{N}, 8.975^{\circ} \mathrm{E}, 115 \mathrm{~m}$ alt.]. Morocco: Chefchaouen, $2009.03\left[35.183^{\circ} \mathrm{N}, 5.300^{\circ} \mathrm{W}\right.$, $400 \mathrm{~m}$ alt.]; Meknes, $1940.02 .02\left[33.894^{\circ} \mathrm{N}, 5.547^{\circ} \mathrm{W}\right.$, $551 \mathrm{~m}$ alt.]; Rabat (Santschi) $\left[33.973^{\circ} \mathrm{N}, 6.845^{\circ} \mathrm{W}\right.$, $84 \mathrm{~m}$ alt.]; Tanger (Alluaud), type $\mathrm{Pl}$. schm. tingitana $\left[35.755^{\circ} \mathrm{N}, 5.819^{\circ} \mathrm{W}, 30 \mathrm{~m}\right.$ alt.]; Tiz-n-Test $-8 \mathrm{~km} \mathrm{~N}$, 1987.05.05, No 13015 [30.889 ${ }^{\circ} \mathrm{N}, 8.370^{\circ} \mathrm{W}, 1810 \mathrm{~m}$ alt.]. Netherlands: Brakel, $2013.02\left[51.820^{\circ} \mathrm{N}, 5.093^{\circ} \mathrm{E}, 2 \mathrm{~m}\right.$ alt.]; Tholen, 2011.05 .27 [51.539 ${ }^{\circ} \mathrm{N}, 4.217^{\circ} \mathrm{E}, 1 \mathrm{~m}$ alt.]; Utrecht, 2006.09.09 [52.09 ${ }^{\circ} \mathrm{N}, 5.12^{\circ} \mathrm{E}, 10 \mathrm{~m}$ alt.]. Portugal: Madeira: Estreito da Calheta, $2009.03\left[32.733^{\circ} \mathrm{N}\right.$, $17.167^{\circ} \mathrm{W}, 350 \mathrm{~m}$ alt.]; Madeira, $1400 \mathrm{~m}$ (Schmitz), paratypes $P l$. schmitzii $\left[33.0^{\circ} \mathrm{N}, 17.0^{\circ} \mathrm{W}, 1400 \mathrm{~m}\right.$ alt.]; Madeira: Garajau (Schmitz), paratypes Pl. schmitzii $\left[32.64^{\circ} \mathrm{N}\right.$, $\left.16.85^{\circ} \mathrm{W}, 230 \mathrm{~m}\right]$; Madeira: Palheiro (Schmitz), paratypes Pl. schmitzii $\left[32.65^{\circ} \mathrm{N}, 16.87^{\circ} \mathrm{W}, 360 \mathrm{~m}\right.$ alt.]. Spain: La Palma: Todoque, $2010.03 .02\left[28.617^{\circ} \mathrm{N}, 17.903^{\circ} \mathrm{W}, 334\right.$ $\mathrm{m}$ alt.]; Tenerife: Las Canadas NP, 1999.06.02 [28.26 ${ }^{\circ} \mathrm{N}$, $16.61^{\circ} \mathrm{W}, 2300 \mathrm{~m}$ alt.]; Sevilla, 2019.06.24 [37.394 ${ }^{\circ} \mathrm{N}$, 5.994 ${ }^{\circ} \mathrm{W}, 10 \mathrm{~m}$ alt.]. Tunisia: Cherichara, 1921.03.27, types $P l$. polygyna $\left[35.637^{\circ} \mathrm{N}, 9.815^{\circ} \mathrm{E}, 255 \mathrm{~m}\right.$ alt.].

Diagnosis and taxonomy (Table 1, key, AntWeb, 2020: CASENT0906252, Figs. 2-4):

$\mathrm{Pl}$. schmitzii has the longest scape and funiculus segments within the species group. The most similar species is $P l$. atlantis, whereas Pl. barbara and Pl. invadens sp. nov. appear more distant and have much shorter scapes (for their status, see there). The material allocated here to Pl. schmitzii (21 samples, 64 specimens) and Pl. atlantis (20 samples, 56 specimens) were investigated by exploratory data analyses (EDAs). Considering absolute head size and all 16 allometrically-corrected shape, pubescence and surface characters, NC-Ward, NC-part.kmeans, NCNMDS-kmeans, a principal component analysis (PCA) and NC-part.hclust confirmed two clusters. The classification of the first four EDAs agreed for each of the 41 samples, whereas NC-part.hclust exposed two samples as indeterminate outliers (Fig. 5). If these two samples were run as wild-cards in a controlling linear discriminant analysis (LDA), they were classified in agreement with the first four EDAs. The classification error of the LDA on an individual level was $0.7 \%$ in 120 workers. All these data are a clear indication of separate species identity of $P l$. schmitzii and Pl. atlantis. Running the type series of seven taxa as wild-cards in the LDA resulted in clear allocations to either cluster. The posterior probabilities for allocation to the $P l$. schmitzii cluster were 1.000 in each of the three paratype series of $P l$. schmitzii from Madeira, 0.999 in the type series of $P l$. polygyna and 1.000 in the type series of $P l$. tingitana, whereas the posterior probabilities for allocation to the $P$ l. atlantis cluster were 1.000 in the type series of $P l$. atlantis, 0.916 in the type series 


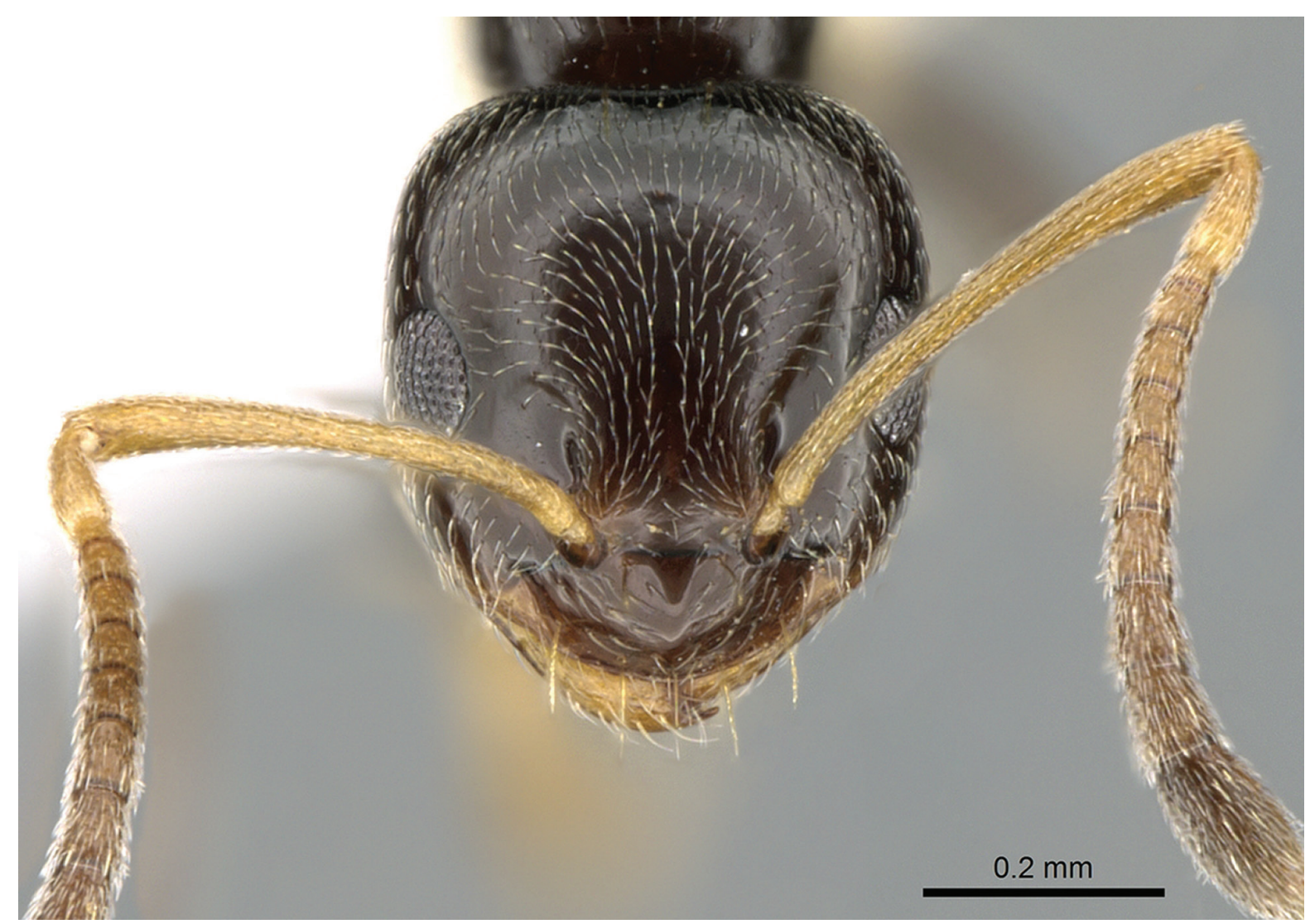

Figure 2. Head of a worker of Plagiolepis schmitzii (image from AntWeb, 2020: CASENT0906252, photographer E. Ortega).

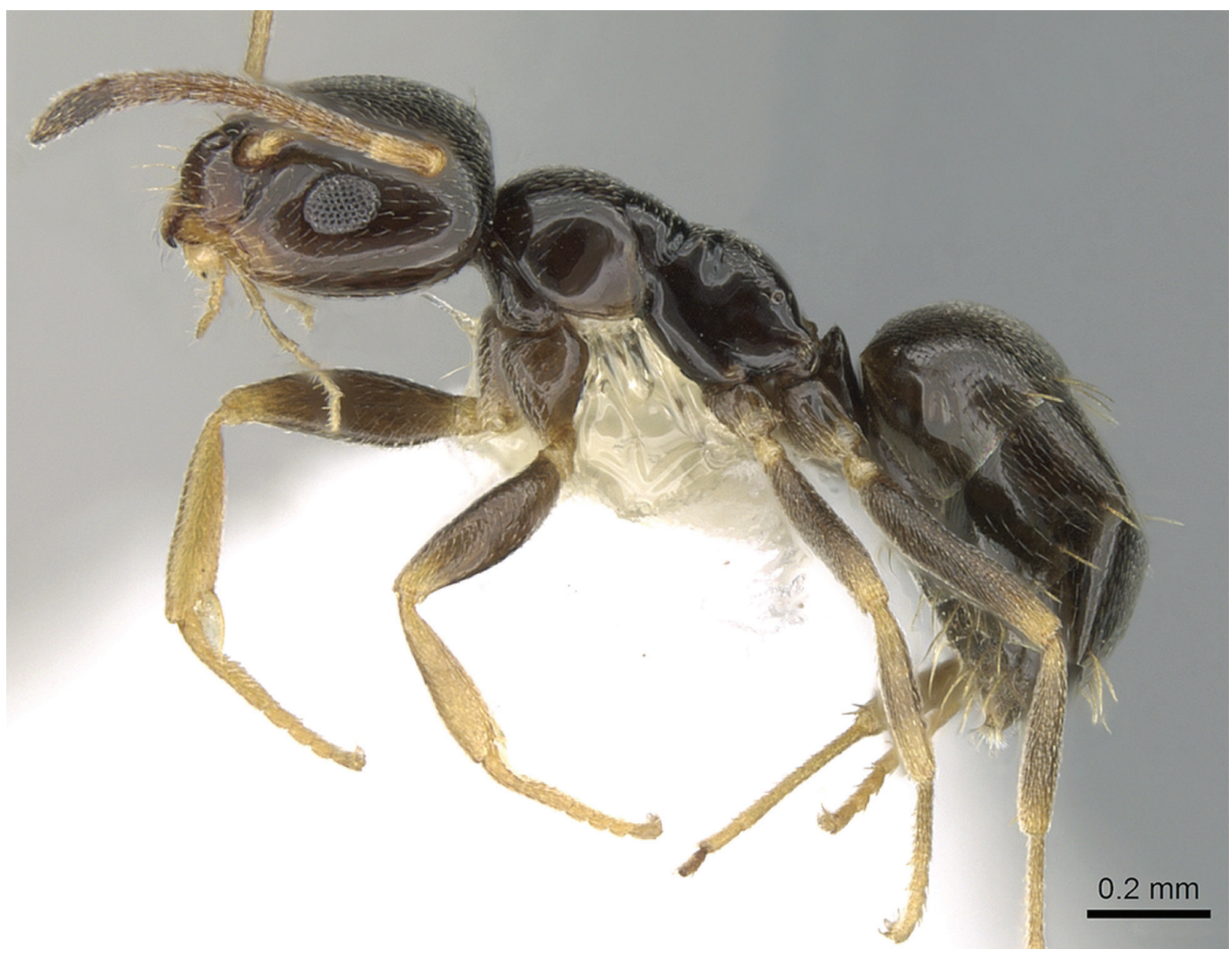

Figure 3. Lateral aspect of a worker of Plagiolepis schmitzii (image from AntWeb, 2020: CASENT0906252, photographer E. Ortega). 


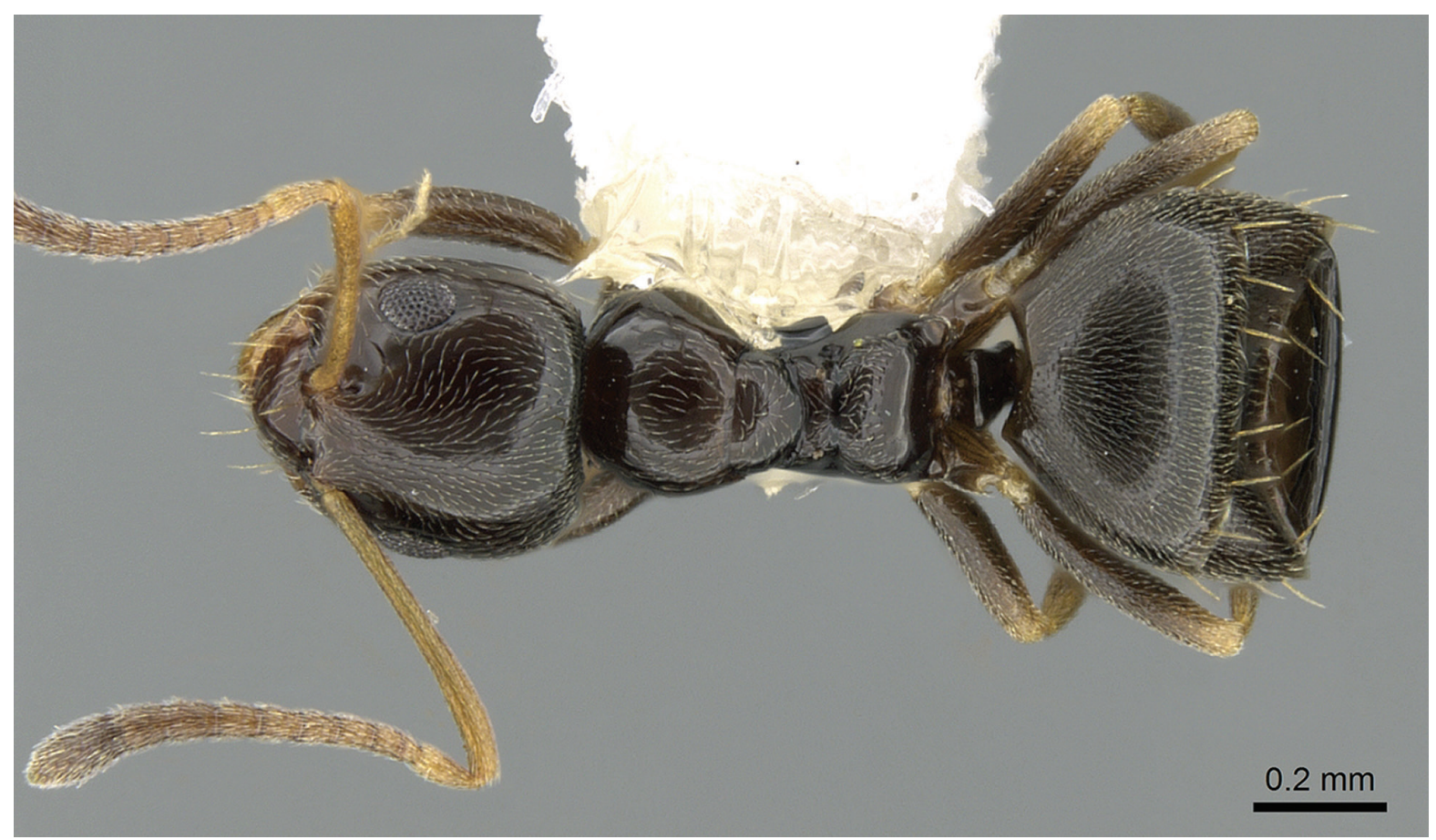

Figure 4. Dorsal aspect of a worker of Plagiolepis schmitzii (image from AntWeb 2020: CASENT0906252, photographer E. Ortega).

of Pl. crosi, 0.994 in the type series of Pl. kabyla and 0.998 in the type series of Pl. perperamus. All five EDAs allocated any type series in agreement with the LDA wild-card runs. As a consequence, $P l$. polygyna and $P l$. tingitana are junior synonyms of $P l$. schmitzii, whereas Pl. crosi, Pl. kabyla and Pl. perperamus are junior synonyms of Pl. atlantis. Without types of Plagiolepis barbara var. madeirensis Emery, 1921 being available, the synonymisation of this taxon with Pl. schmitzii is highly probable for two reasons: (1) the scape is very long: the data of SL and CW, as they can be derived with minimum distortions from the CASENT0905140 photo of the Pl. $b$. madeirensis type, are within the $P l$. schmitzii cluster and outside the cluster formed by Pl. atlantis, Pl. invadens sp. nov. and Pl. barbara; (2) Madeira seems to be inhabited by only a single, very abundant Plagiolepis species which is to be named Pl. schmitzii.

Distribution and biology. According to direct investigation of voucher specimens, $P l$. schmitzii is distributed from Madeira and the Canaries across West Mediterranean Africa east to Tunisia. There are anthropogenous introductions north of $46^{\circ} \mathrm{N}$. In Germany, it has been found so far only in houses, with workers occasionally foraging outdoors. However, year-round outdoor nesting has been recently reported from two sites in the Netherlands (Jinze Noordijk pers. comm. 2020). Accordingly, there is a clear potential for becoming an established neozoon in NW and Central Europe in the context of global warming. Polygyny and polydomy with colony territories over several houses is confirmed for populations in the Netherlands and Germany. The population from Madeira, Estreito da Calheta is obliga- tory polygynous and highly polyandrous (a queen may have up to 14 different mates), whereas the population from Chefchaouen in Morocco is facultatively polygynous and moderately polyandrous (Thurin et al. 2011). These authors stated that relatedness within colonies remains high because of sib-mating and relatedness of the male mates of a queen (fixation index $F_{\text {it }}=0.24$ in the Madeiran and 0.26 in the Moroccan population). Small size, polygyny with intranidal mating and broad food spectrum are pre-adaptations for a career as a tramp species. Pl. schmitzii is everywhere present in Madeira and rivals there in abundance with Lasius cf. grandis Forel.

\section{Plagiolepis atlantis Santschi, 1920}

Plagiolepis maura var. atlantis Santschi, 1920 Three gyne and five worker syntypes were investigated from NHM Basel, labelled "Plagiolepis Type maura Sants v. atlantis Santi", "13.”, "Tunisie Dir el Kef Dr. F. Santschi”, “mai 1913”, “type”, “ANTWEB CASENT0912421",

Plagiolepis schmitzii crosi Santschi, 1920 [syn. atlantis] Three type workers were investigated from NHM Basel, labelled "Plagiolepis crosi. Sants", "Algerie Mascara A-Cros." and "ANTWEB CASENT0912429",

Plagiolepis pallescens var. kabyla Santschi, 1920 [syn. atlantis] Three type workers were investigated from NHM Basel, labelled "Plagiolepis maura Sant v. kabyla Sant type”, "Tunisie Ain Draham Santschi 1913”, “Type”, “ANTWEB CASENT0912423”. The type specimens are pale yellowish and thus paler than usually seen.

Plagiolepis perperamus Salata et al., 2018 [syn. atlantis] Three paratypes were investigated from the holotype nest, labelled "LBC-GR00042", 
“GREECE NW Crete | 3 km S Askifou $800 \mathrm{~m}$ a.s.1.| 35'16'N/24¹0'E | 1 V 2007. L.\& M.L. Borowiec"; depository DBU Wroclaw.

Material examined. A total of 20 samples with 56 workers were subject to morphometric investigation.

Algeria: Azeffoun, $1986.04 .13\left[36.89^{\circ} \mathrm{N}, 4.41^{\circ} \mathrm{E}\right.$, $5 \mathrm{~m}$ alt.]; Chrea, $1965.05 .14\left[36.47^{\circ} \mathrm{N}, 2.91^{\circ} \mathrm{E}, 900 \mathrm{~m}\right.$ alt.]; Col de Temet, 1986.04.06, samples No 12518$12522\left[35.596^{\circ} \mathrm{N}, 0.050^{\circ} \mathrm{E}, 1600 \mathrm{~m}\right.$ alt.]; Dshebel Chelia, 1986.04.06, No $12509\left[35.32^{\circ} \mathrm{N}, 6.66^{\circ} \mathrm{E}, 2100 \mathrm{~m}\right.$ alt.]; Marnia, Cap. Boitel (Santschi) $\left[34.85^{\circ} \mathrm{N}, 1.73^{\circ} \mathrm{W}\right.$, $410 \mathrm{~m}$ alt.]; Mascara, 1920 , type of $P l$. crosi $\left[35.40^{\circ} \mathrm{N}\right.$, $0.14^{\circ} \mathrm{E}, 603 \mathrm{~m}$ alt.]. Greece: Agios Mamas, salines, $2009.09 .04\left[40.217^{\circ} \mathrm{N}, 23.333^{\circ} \mathrm{E}, 4 \mathrm{~m}\right.$ alt.]; Agios Niko-

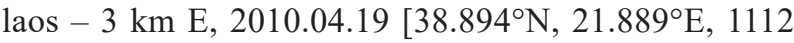
$\mathrm{m}$ alt.]; Askifou-3 km S, 2007.05.01, type $P l$. perperamus $\left[35.267^{\circ} \mathrm{N}, 24.176^{\circ} \mathrm{E}, 800 \mathrm{~m}\right.$ alt.]; Kassandra, Sividri, $2009.08 .25\left[40.033^{\circ} \mathrm{N}, 23.350^{\circ} \mathrm{E}, 6 \mathrm{~m}\right.$ alt.]; Lesbos: Petri, $2012.05 .23\left[39.323^{\circ} \mathrm{N}, 26.192^{\circ} \mathrm{E}, 158\right.$ $m$ alt.]. Morocco: Sidi Smail-8 km N, 1987.05.04, No $12991\left[32.873^{\circ} \mathrm{N}, 8.876^{\circ} \mathrm{W}, 137 \mathrm{~m}\right.$ alt.]; Tiz-n-Test-8 $\mathrm{km} \mathrm{N}, 1987.05 .05$ [30.889 ${ }^{\circ} \mathrm{N}, 8.370^{\circ} \mathrm{W}, 1810 \mathrm{~m}$ alt.]. Tunisia: Ain Draham, 1913, type Pl. kabyla $\left[36.779^{\circ} \mathrm{N}\right.$, $8.687^{\circ} \mathrm{E}, 764 \mathrm{~m}$ alt.]; Dir el Kef, 1913.05, type Pl. atlantis $\left[36.17^{\circ} \mathrm{N}, 8.70^{\circ} \mathrm{E}, 594 \mathrm{~m}\right.$ alt.]. Turkey: Ankara (Santschi) $\left[39.93^{\circ} \mathrm{N}, 32.86^{\circ} \mathrm{E}, 890 \mathrm{~m}\right.$ alt.].

Diagnosis and taxonomy (Table 1, key, AntWeb, 2020: pictures of specimen CASENT0912421):

The clear separation from $\mathrm{Pl}$. schmitzii by exploratory and hypothesis-driven data analyses has been demonstrated above. As Santschi described the synonyms $\mathrm{Pl}$. atlantis, $\mathrm{Pl}$. crosi and $\mathrm{Pl}$. kabyla within the same paper (Santschi 1920), the priority of $P l$. atlantis was fixed by the reviser's decision. $\mathrm{Pl}$. atlantis differs from $\mathrm{Pl}$. barbara by having smaller eyes and larger preocular and postocular distance and from $\mathrm{Pl}$. invadens sp. nov. by a much longer $3^{\text {rd }}$ funiculus segment. For the clear separation from these species by exploratory data analyses, see there.

It is my duty here to comment on the paper of Salata et al. (2018). These authors introduced a new species $P l$. perperamus and made attempts to suggest its heterospecificity from $P l$. schmitzii. Regarding the morphological separation of the two entities, they wrote nothing but two sentences: “...their separation using morphological characters such as size, body colouration and gaster setosity is very challenging (Table 1). In most cases both species differ in length of gaster setosity. In $P$. perperamus setae are long enough to cover at least $1 / 2$ of the length of following setae and in P. schmitzii they cover approximately $1 / 4$ of the length of the following setae". Firstly, I agree with Salata et al. (2018) that the separation is challenging. Data of absolute measurements and body ratios given in their table 1 show, indeed, a huge interspecific overlap for any presented character, making a reader believe that these characters could be useless for species separation. Secondly, the authors are not familiar with the accepted terminology of ant morphology. What they have called "setosity" and "setae" truly refer to pubescence which dramatically differs in size, spatial arrangement and microstructure of the hairs from those structures consistently named by dead and living ant taxonomist as true setae or pilosity. Thirdly, if only the length of gastral pubescence hairs were believed to be a rather good separating character, why did Salata et al. not present concrete data in their table 1? Having measured these data carefully and in a larger sample, they would have become aware that a weak difference of mean values is invalidated in its taxonomic significance by a huge overlap range. According to investigations presented here, absolute length of pubescence hairs on dorsum of $1^{\text {st }}$ gaster tergite (PLG) in micron as the mean of seven measurements per individual and over the whole geographic range is $30.6 \pm 2.0[26.5,35.4]$ in 64 workers of Pl. schmitzii and $32.8 \pm 2.3[28.0,38.1]$ in 56 workers of Pl. atlantis (= $P l$. perperamus). Fourthly, the full absence in the text of concrete verbal or numeric data on characters of type specimens of taxa of the Pl. schmitzii group in the paper of Salata et al. (2018) indicates that there was no thorough direct investigation of type specimens. There was putatively a subjective eye inspection by Sebastian Salata during his visits of NHM Basel and MHN Genève, but the curators of both museums Isabelle Zürcher and Bernard Landry confirmed that there has been no loan of any Plagiolepis type specimen by one of the three co-authors.

In the absence of a conclusive morphological argumentation, Salata et al. (2018) used a survey of Mediterranean climate variables, showing that precipitation in the coldest quarter of the year significantly differs between the East and West Mediterranean zone. The conclusion of Salata et al. (2018) from this was that, amongst those Mediterranean Plagiolepis ants with dense pubescence on gaster tergites, there were two different allopatric or parapatric species, because "climate niches" in the east and west of the area differed. The applied taxonomic working philosophy reads as follows: if we cannot show a morphological difference in a sample of animals distributed over a certain geographic area, it is sufficient to demonstrate a significant difference of regional meteorological data to subdivide this sample into different species and that describing a new species can be done without a thorough direct investigation of type specimens of some 12 candidate taxa for senior synonymy.

Distribution and biology. $\mathrm{Pl}$. atlantis has obviously a more eastern distribution than $P l$. schmitzii, but the ranges of both species overlap in North Africa over at least $1800 \mathrm{~km}\left(9^{\circ} \mathrm{W}\right.$ to $\left.10^{\circ} \mathrm{E}\right)$. Pl. atlantis is so far not known to occur as a tramp species in sub-Mediterranean or temperate Europe - neither outdoors nor in houses. Occurrence east of Turkey seems credible, but needs confirmation by reliably-determined voucher specimens. Salata et al. (2018) reported it to nest in soil, usually below stones and to be associated with humid areas overgrown by macchia or forests. Colonies are polygynous. 


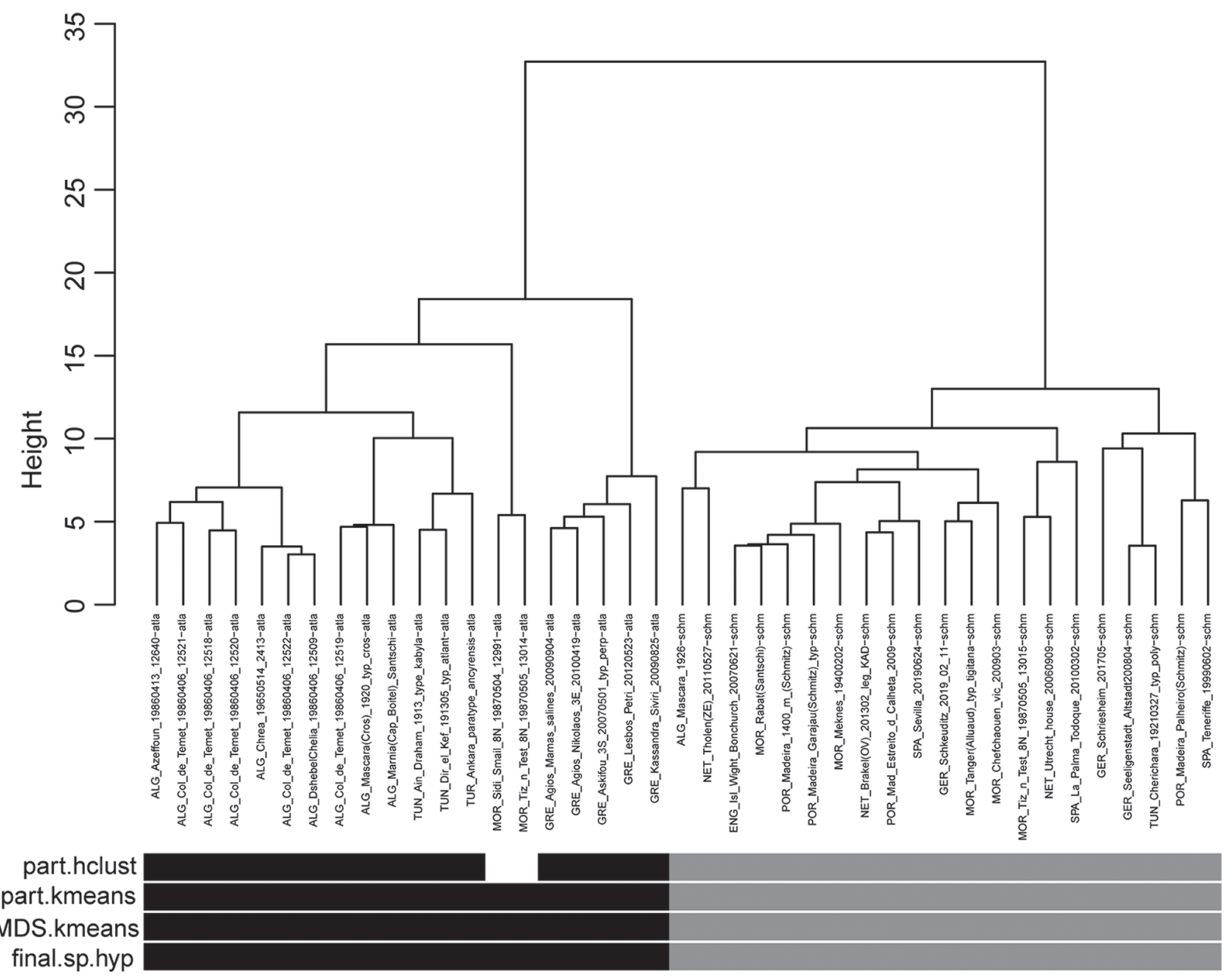

Figure 5. Results of four variants of NC-clustering: NC-Ward (hierarchical, tree shown), NC-part.hclust (hierarchical), NC-part. kmeans (iterative vector-quantisation), NC-NMDS (non-metric scaling); 21 nest samples of Plagiolepis schmitzii (grey bars) and of 20 nest samples of $P l$. atlantis (black bars). Outliers in NC-part.hclust are given by the white gap.

\section{Plagiolepis invadens sp. nov.}

http://zoobank.org/632BFBD8-D80E-4AA5-B16B-46D0E2662D07

Etymology. Meaning "invasive" (from Latin invado) The type colony in SW Germany is an anthropogenous introduction from an unknown origin, shows circannual outdoor nesting, but invaded houses in large numbers during the extremely dry summers of 2018 and 2019.

Type material. Holotype plus one paratype worker on the same pin labelled "GER: $49.65703^{\circ} \mathrm{N}, 8.41775^{\circ} \mathrm{E}$ Hofheim, $92 \mathrm{~m}$, supercolony in garden, known since about 4 years, leg. Heller 2019.08" and "Holotype (top) and paratype of Plagiolepis invadens Seifert"; three paratype workers from the same collecting data; five paratype workers labelled "GER: $49.65703^{\circ} \mathrm{N}$, $8.41775^{\circ} \mathrm{E}$ Hofheim, $92 \mathrm{~m}$, supercolony in garden, known since about 5 years, leg. Heller 2020.06"; all material is stored in SMN Görlitz.

Diagnosis and taxonomy (Table 1, key, Figures 6-8). With narrowly-spaced basal pits of pubescence hairs (BPdG $15.6 \mu \mathrm{m})$, low pubescence distance (sqPDG 2.69) and the $4^{\text {th }}$ funiculus segment not being much longer than the $3^{\text {rd }}(\mathrm{F} 4 / \mathrm{F} 3$ 1.346), Pl. invadens sp. nov. is clearly separable from the species of the $P l$. pygmaea and $P l$. pallescens group and is characterised as a member of the Pl. schmitzii group. It is outstanding within the latter group by the very short $3^{\text {rd }}$ funiculus segment: primary ratios of $\mathrm{F} 3 / \mathrm{CS}$ are $7.37 \pm 0.43[6.85,8.04] \%$ in ten workers of $P l$. invadens sp. nov., but $9.78 \pm 0.61$ $[8.59,11.59] \%$ in 124 specimens of the other three $P l$. schmitzii group species. The most similar species is $P l$. atlantis and it may be asked if there is a risk of synonymy, considering that the description of $P l$. invadens sp. nov. is based on workers from only a single supercolony. Running a PCA, considering absolute head size and the 16 RAV-corrected shape, pubescence and surface characters, resulted in a strong separation of all individuals by the $1^{\text {st }}$ principal component:

Pl. invadens sp. nov. $-1.946 \pm 0.343[-2.477,-1.368] \mathrm{n}=10$ Pl. atlantis $\quad 0.348 \pm 0.592[-1.020,1.338] \mathrm{n}=56$.

This clear result (ANOVA, $\mathrm{F}_{1,64}=140.4, \mathrm{p}<0.001$ ), achieved without character selection, is a reasonable indication of heterospecificity. A vector considering the $1^{\text {st }}$ and $3^{\text {rd }}$ principal component with $1.893^{*} \mathrm{PC} 1+$ 
Table 1. RAV-corrected morphometric data of worker individuals of the Plagiolepis schmitzii complex given as arithmetic mean \pmstandard deviation [minimum, maximum]; $\mathrm{n}=$ number of individuals. $\mathrm{F}$ values and significance levels $\mathrm{p}$ are from a univariate ANOVA and evaluate the differences between Pl. atlantis and Pl. invadens sp. nov.

\begin{tabular}{|c|c|c|c|c|c|}
\hline & barbara $(\mathrm{n}=7)$ & schmitzii $(n=64)$ & atlantis $(\mathrm{n}=56)$ & ANOVA $\mathrm{F}_{1,64}, \mathbf{p}$ & invadens sp. nov. $(\mathrm{n}=10)$ \\
\hline $\mathrm{CS}[\mu \mathrm{m}]$ & $488 \pm 39[428,527]$ & $466 \pm 39[390,548]$ & $455 \pm 33[404,533]$ & 0 , n.s. & $455 \pm 26[408,497]$ \\
\hline $\mathrm{CL} / \mathrm{CW}_{0.45}$ & $1.106 \pm 0.012[1.092,1.128]$ & $1.113 \pm 0.023[1.066,1.173]$ & $1.108 \pm 0.024[1.062,1.193]$ & 0.01 , n.s. & $1.108 \pm 0.013[1.090,1.132]$ \\
\hline $\mathrm{dTP} / \mathrm{CS}_{0.45}$ & $0.502 \pm 0.012[0.478,0.513]$ & $0.508 \pm 0.011[0.487,0.535]$ & $0.502 \pm 0.011[0.480,0.538]$ & 0.80, n.s. & $0.499 \pm 0.009[0.479,0.509]$ \\
\hline $\mathrm{dAN} / \mathrm{CS}_{0.45}$ & $0.243 \pm 0.006[0.235,0.253]$ & $0.243 \pm 0.007[0.222,0.255]$ & $0.241 \pm 0.008[0.224,0.266]$ & $8.61,0.005$ & $0.249 \pm 0.005[0.241,0.256]$ \\
\hline $\mathrm{EL} / \mathrm{CS}_{0.45}$ & $0.321 \pm 0.015[0.301,0.336]$ & $0.286 \pm 0.010[0.267,0.311]$ & $0.263 \pm 0.013[0.240,0.299]$ & 1.12 , n.s. & $0.259 \pm 0.004[0.254,0.264]$ \\
\hline $\mathrm{PrOc} / \mathrm{CS}_{0.45}$ & $0.219 \pm 0.009[0.207,0.231]$ & $0.239 \pm 0.011[0.210,0.262]$ & $0.247 \pm 0.012[0.218,0.273]$ & 1.43 , n.s. & $0.252 \pm 0.006[0.241,0.264]$ \\
\hline $\mathrm{PoOc} / \mathrm{CL}_{0.45}$ & $0.341 \pm 0.008[0.334,0.356]$ & $0.359 \pm 0.008[0.341,0.381]$ & $0.376 \pm 0.012[0.351,0.399]$ & 1.28 , n.s. & $0.371 \pm 0.006[0.361,0.381]$ \\
\hline $\mathrm{SL} / \mathrm{CS}_{0.45}$ & $0.945 \pm 0.019[0.920,0.971]$ & $1.034 \pm 0.020[0.980,1.072]$ & $0.970 \pm 0.024[0.920,1.011]$ & 36.72, 0.000 & $0.923 \pm 0.011[0.900,0.936]$ \\
\hline $\mathrm{F} 2 / \mathrm{CS}_{0.45}[\%]$ & $7.16 \pm 0.51[6.61,7.89]$ & $7.93 \pm 0.57[6.54,9.11]$ & $7.11 \pm 0.39[6.16,8.15]$ & 0.49 , n.s. & $7.21 \pm 0.44[6.65,8.06]$ \\
\hline $\mathrm{F} 3 / \mathrm{CS}_{0.45}[\%]$ & $9.12 \pm 0.28[8.64,9.39]$ & $10.17 \pm 0.48[9.20,11.55]$ & $9.36 \pm 0.35[8.71,10.32]$ & $\mathbf{2 6 5 . 5}, 0.000$ & $7.36 \pm 0.42[6.88,8.11]$ \\
\hline $\mathrm{F} 4 / \mathrm{CS}_{0.45}[\%]$ & $10.88 \pm 0.34[10.34,11.32]$ & $12.27 \pm 0.50[11.04,13.23]$ & $10.96 \pm 0.39[10.17,11.99]$ & 61.8, 0.000 & $9.88 \pm 0.43[9.22,10.50]$ \\
\hline $\mathrm{F} 4 / \mathrm{F}_{0.45}$ & $1.193 \pm 0.024[1.158,1.222]$ & $1.208 \pm 0.060[1.052,1.357]$ & $1.172 \pm 0.046[1.054,1.312]$ & $\mathbf{8 9 . 9}, 0.000$ & $1.346 \pm 0.086[1.218,1.511]$ \\
\hline $\mathrm{ML} / \mathrm{CS}_{0.45}$ & $1.205 \pm 0.015[1.190,1.226]$ & $1.234 \pm 0.034[1.160,1.322]$ & $1.174 \pm 0.034[1.105,1.279]$ & 0.01, n.s. & $1.175 \pm 0.034[1.127,1.248]$ \\
\hline $\mathrm{MW} / \mathrm{CS}_{0.45}$ & $0.640 \pm 0.017[0.609,0.656]$ & $0.629 \pm 0.018[0.581,0.669]$ & $0.653 \pm 0.022[0.607,0.695]$ & 28.82, 0.000 & $0.615 \pm 0.012[0.601,0.635]$ \\
\hline $\mathrm{PLG} / \mathrm{CS}_{0.45}[\%]$ & $7.22 \pm 0.28[6.84,7.58]$ & $6.73 \pm 0.46[5.82,7.77]$ & $7.30 \pm 0.49[6.38,8.25]$ & 0.93 , n.s. & $7.46 \pm 0.49[6.74,8.07]$ \\
\hline $\mathrm{sqPDG}_{0.45}$ & $3.50 \pm 0.33[3.05,4.06]$ & $2.87 \pm 0.31[2.40,3.76]$ & $2.89 \pm 0.19[2.55,3.28]$ & $9.61,0.003$ & $2.70 \pm 0.08[2.56,2.80]$ \\
\hline $\mathrm{BPdG}_{0.45}$ & $19.81 \pm 1.87[17.8,23.4]$ & $15.78 \pm 2.04[12.7,21.5]$ & $16.53 \pm 1.28[14.4,19.4]$ & $4.94,0.030$ & $15.60 \pm 0.78[14.7,16.9]$ \\
\hline
\end{tabular}

$0.563 * \mathrm{PC} 3$ provides an even stronger separation (ANOVA, $\left.\mathrm{F}_{1,64}=189.6, \mathrm{p}<<0.001\right)$ :

Pl. invadens sp. nov. $-4.010 \pm 0.649[-4.962,-2.932] \mathrm{n}=10$ Pl. atlantis $\quad 0.716 \pm 1.046[-1.597,2.681] \mathrm{n}=56$.

Further descriptive statements. Head moderately elongated (CL/CW 1.105). Scape shorter than in related species (SL/CS 0.923). Eye medium-sized (EL/CS 0.258). Mesosoma width smaller than in related species (MW/CS 0.615). Cuticular surface of head, mesosoma, coxae and femora brilliantly shining and with a dilute appressed to decumbent pubescence. Scape and tibiae with a more dense decumbent pubescence. Head, scape, femora and mesosoma varying from dark brown with yellowish tinge to almost black. Antennal funiculus, coxae, tibiae and sometimes pronotum pale yellowish-brown.

Biology. Pl. invadens sp. nov. is known so far from only a single supercolony in SW Germany in a settlement with about $30 \%$ greenery and $70 \%$ building or sealed area. Residents became aware of the ants in the gardens in about 2016. Ants were not perceived as plagues inside the houses in the years 2016 and 2017, but masses of workers invaded houses during the extremely dry summers of 2018 and 2019 in such numbers that the residents tried to get rid of the ants by using vacuum cleaners. Gerhard Heller observed in September 2019 and June 2020 the presence of a true supercolony with millions of workers and runways stretching along the roadside of at least two properties. Preferred nest sites were the most humid spots with much greenery where the ants constructed small hills made of soil ejections. The residents also reported that "black ants being clearly bigger" than the Plagiolepis - presumably Lasius niger (Linnaeus, 1758) - vanished after the development of the Pl. invadens sp. nov. supercolony. The species is obviously able to long-time survival under outdoor conditions within the current climatic scenario and will have to be considered as established neozoon in Germany if efforts to eradicate the population fail. Reproductive biology, demography and food ecology of Pl. invadens sp. nov. are not studied so far, but are expected to show the traits described in the concluding chapter of this paper.

Comments. There is certainly some risk describing a new species based upon a single colony. Yet, this risk is calculable and apparently low. Firstly, the separation in the PCA is very strong and the next similar species $\mathrm{Pl}$. atlantis was available for this PCA in a large sample. Secondly, the reported diagnostic characters, which are homogenously distributed over the colony in space and time, are unlikely to represent a spontaneous mutant. This would require a single founding queen which was homozygous for at least one allele, both determining length of scape and funiculus segments and slenderness of the mesosoma and it would require propagation of this mutant over millions of individuals in the supercolony. Thirdly, considering the Palaearctic region, 10 taxa of the Pl. schmitzii group (reported here) and 14 taxa of the Pl. pallescens and $P l$. pygmaea group have been checked and excluded as senior synonyms (Kirschner et al. in prep.). There is only one taxon which seems to pose some risk: Plagiolepis barbara var. pyrenaica Emery, 1921, collected in the Eastern Pyrenees. Assessing a photo of a type specimen (AntWeb 2020), it seems to have a gastral pubescence density approaching the situation in the Pl. schmitzii group, but further conclusions are impossible. A direct investigation of type specimen(s), which should exist in MCSN Genoa, is currently not possible due to long-term effects caused by the COVID19 pandemic. Fourthly, scrutinising the photos of type specimens of 44 Plagiolepis taxa from remote zoogeographic regions (AntWeb 2020), there is no apparent candidate taxon for senior synonymy. All these taxa differ clearly. Arranged in alphabetic order of species-level taxon names, their unique specimen identifiers were CASENT0909850, CASENT0132814, CASENT0917582,CASENT0909845,CASENT0217200, 


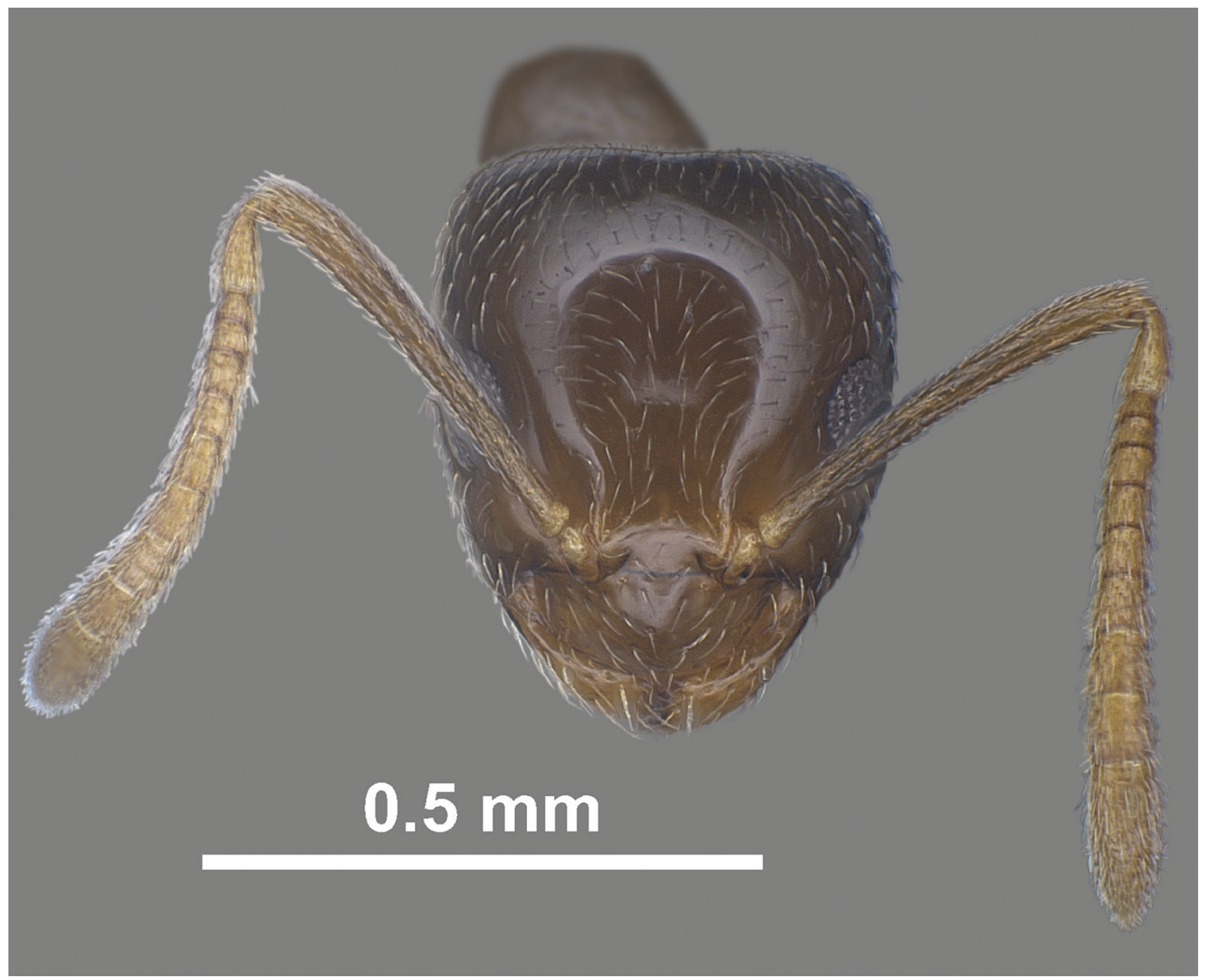

Figure 6. Head of the holotype worker of Plagiolepis invadens sp. nov.

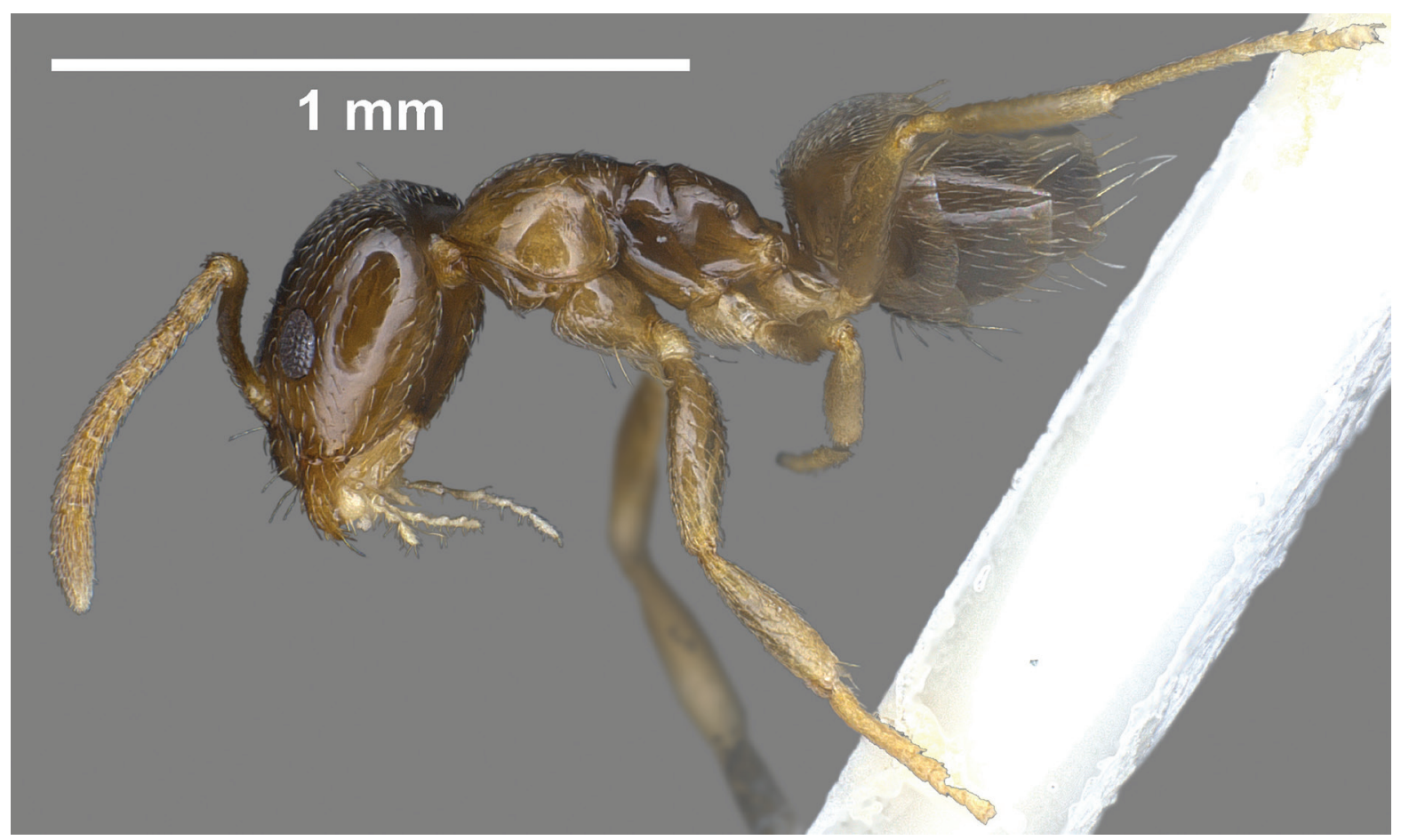

Figure 7. Lateral aspect of the holotype worker of Plagiolepis invadens sp. nov. 


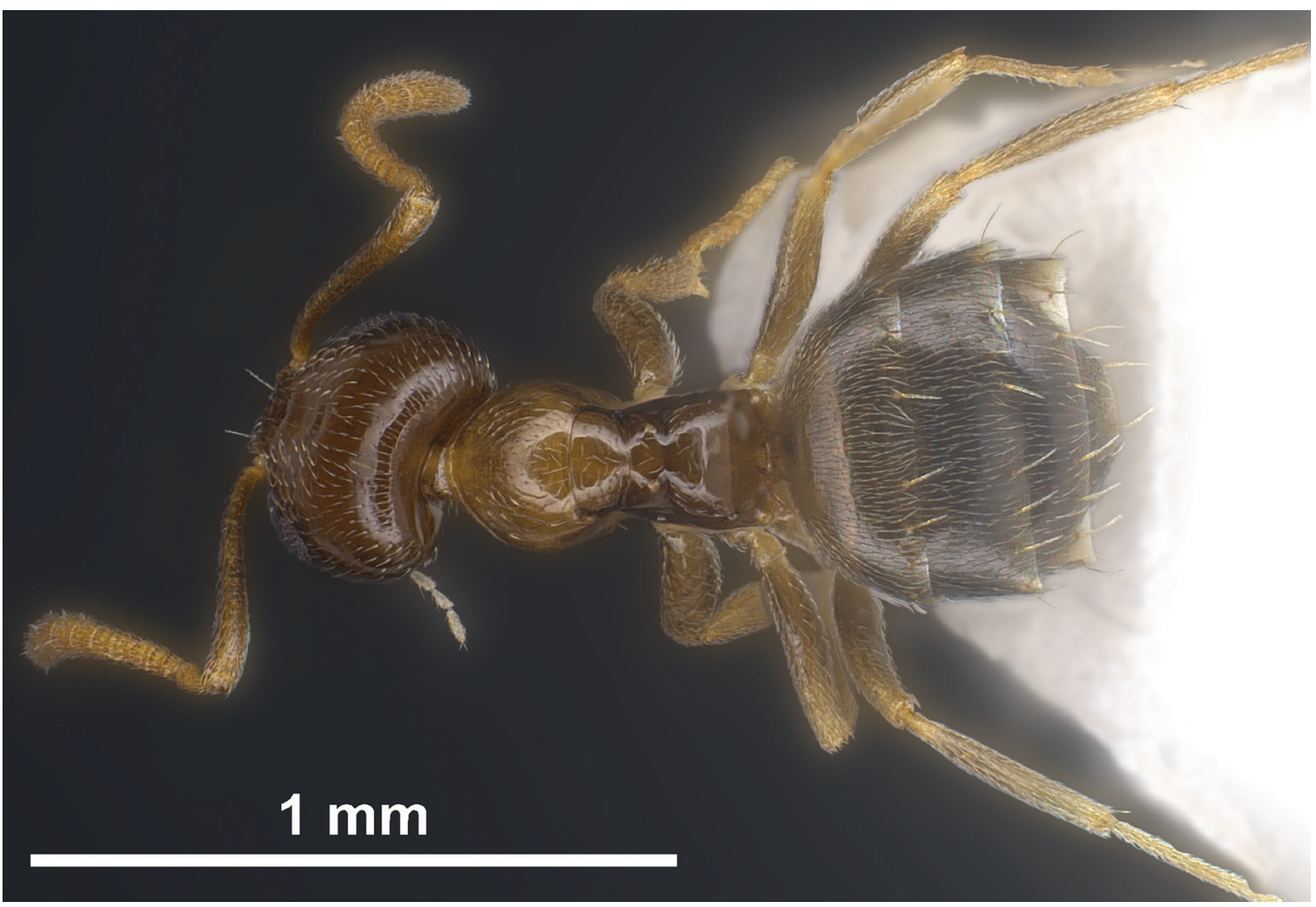

Figure 8. Dorsal aspect of the holotype worker of Plagiolepis invadens sp. nov.

CASENT0281160, CASENT0909846, CASENT0909847, CASENT0917579, CASENT0915713, CASENT0903144, CASENT0917578, CASENT0906247, CASENT0912417, CASENT0281161, CASENT0909848, CASENT0917484, CASENT0101305, CASENT0903146, CASENT0916654, CASENT0912418, CASENT0235986, CASENT0913616, CASENT0905142, CASENT0905143, CASENT0909852, CASENT0909861,CASENT0906471, CASENT0912419, CASENT0217737, CASENT0101224, CASENT0909853, CASENT0909854, CASENT0912411, GBIF-D/FoCol 2225, CASENT0787965, CASENT0903145, CASENT0906251,CASENT0905141, CASENT0217738, CASENT0909863, CASENT0912412, CASENT0909864 and CASENT0917485.

\section{Plagiolepis barbara Santschi, 1911}

Plagiolepis pygmaea var. barbara Santschi, 1911 Two type workers were investigated from NHM Basel, labelled "Kairouan Tunisie Santschi. 1903", "Plagiolepis barbara type Sant", "v. barbara type Sant", “ANTWEB CASENT0912428 top specimen".

Plagiolepis maura Santschi, 1920 [syn. barbara] The collection data published by Santschi are "Maroc: Mogador (Vaucher), avril 1905, types w, m,g. Tanger (Vaucher), Rabat (Thery)". One type worker was morphometrically investigated from NHM Basel, labelled "4.905 Mogador Vaucher", "Plagiolepis maura type Sants", “ANTWEB CASENT0912424". This specimen belongs to the true type series as Santschi published only the Mogador specimens as types.
Furthermore, no specimens in the Santschi collection from Tanger and Rabat are labelled as Pl. maura or as types.

Material examined. A total of three samples with seven workers were subject to morphometric investigation.

Morocco: Mogador, 1905.04 (Vaucher), type $\mathrm{Pl}$. maura $\left[31.508^{\circ} \mathrm{N}, 9.76^{\circ} \mathrm{W}, 4 \mathrm{~m}\right.$ alt.]. Tunisia: Kairouan, 1903 , type $P l$. barbara $\left[35.671^{\circ} \mathrm{N}, 10.099^{\circ} \mathrm{E}, 67 \mathrm{~m}\right.$ alt.]; Kairouan, 1920.03 .07 [35.671 ${ }^{\circ} \mathrm{N}, 10.099^{\circ} \mathrm{E}, 67 \mathrm{~m}$ alt.].

Diagnosis and taxonomy (Table 1, key, AntWeb, 2020: pictures of specimens CASENT0912424 and CASENT0912428):

$P l$. barbara differs from $P l$. schmitzii by a much shorter scape and a shorter postocular distance, from $P l$. atlantis by larger eye and from $P l$. invadens sp. nov. by larger eye and much longer $3^{\text {rd }}$ funiculus segment. The most similar species is $\mathrm{Pl}$. atlantis and it may be asked if there is a risk of synonymy, considering the small sample size in Pl. barbara. This risk is low.

Running a PCA with absolute head size and the 16 RAV-corrected shape, pubescence and surface characters, there is a very strong separation of all individuals by the first principal component (ANOVA, $F_{1,61} 149.0, p<<0.001$ ):
Pl. atlantis $-0.295 \pm 0.532[-1.337,0.758] \mathrm{n}=56$
Pl. barbara $2.363 \pm 0.638[1.564,3.311] \mathrm{n}=7$

Distribution and biology. Distributed in west Mediterranean Africa. Biology unknown. 


\section{Excursus: The tramp-species-supercolony syndrome in Plagiolepis}

Plagiolepis invadens sp. nov. is, together with Pl. schmitzii and Pl.pygmaea, the third Plagiolepis species known from areas north of the Alps to show anthropogenous introduction, supercoloniality and permanent outdoor nesting throughout the year. The situation in Pl. schmitzii is commented in the species chapter above and is not entirely new, but the case of $P$. pygmaea with an apparently new dynamics towards supercoloniality in introduction areas needs commentary. According to samples sent to me during last the three decades and deposited in SMN Görlitz, Pl. pygmaea has been anthropogenously introduced to settlements and inner urban areas - most of these are situated far north of its natural range. The first year of observation and localities are 1993 in Mainz-Hechtsheim $\left(49.97^{\circ} \mathrm{N}, 8.27^{\circ} \mathrm{E}\right), 2007$ in Berlin-Köpenick $\left(52.49^{\circ} \mathrm{N}\right.$, $\left.13.57^{\circ} \mathrm{E}\right), 2011$ in Hanhofen $\left(49.31^{\circ} \mathrm{N}, 8.34^{\circ} \mathrm{E}\right), 2019$ in Haßloch $\left(49.37^{\circ} \mathrm{N}, 8.24^{\circ} \mathrm{E}\right), 2019$ in Zurich $\left(47.39^{\circ} \mathrm{N}\right.$, $\left.8.49^{\circ} \mathrm{E}\right)$ and 2020 in Lützelsachsen $\left(49.52^{\circ} \mathrm{N}, 8.66^{\circ} \mathrm{E}\right)$. In three cases, introduction with plant material was apparent and, in the last two localities (Zurich and Lützelsachsen), the formation of supercolonies was observed.

Are there general traits or pre-adaptations in Plagiolepis ants for a career as a tramp species, for eventual transformation to supercoloniality and for developing a competitive advantage - traits that might also explain the sudden emergence of $P l$. invadens sp. nov. as if from nowhere? There are four Plagiolepis species with known mating scenarios and colony demography: the Palaearctic Pl. pygmaea, $P l$. cf. taurica and Pl. schmitzii, studied by Thurin et al. (2011) and Pl. alluaudi Emery, 1894 from the tropics of the old world observed by Buschinger (2012) in greenhouses of the Darmstadt Botanical Garden. All four species share characters facilitating anthropogenous introduction and transition to supercoloniality: (a) very small size, (b) wide food spectrum, (c) strong tendency for intranidal mating and (d) high degree of polygyny. A single medium-sized flower pot allows long-term survival and reproduction of these tiny ants and, placed at the right spot, it may serve as a beach head for supercolony formation by nest splitting.

Another factor is probably also important for the success of Plagiolepis ants. At least for Pl. taurica, we have direct observations that an unidentified secretion emitted from the gaster tip is extremely toxic and repellent to other ant species (Seifert 2018) and which may explain that it is tolerated within the territories of dominant ants. Pl. taurica may share a bait or trophobiont colony with so-called dominant ants or even displace these. These observations are repeated in other species: $P l$. pygmaea was the only ant species allowed to co-exist and move freely within the territory of a Linepithema humile (Mayr, 1868) supercolonies in France and Spain (Charrier et al. 2020) and Pl. alluaudi was observed in the Bermudas (Smith 1957), New Caledonia (Le Breton 2003) and the Great Barrier Reef islands (Burwell et al. 2012) to show, in contrast to other ants, no population decrease in the presence of dominant supercolonial Pheidole megacephala (Fabricius, 1793).

\section{Acknowledgements}

I wish to thank Isabelle Zürcher (NHM Basel), Bernard Landry (MNH Genève) and Lech Boroviec (DBU Wrocław) for quickly enabling loans of type specimens. I kindly acknowledge the support given by Roland Schultz who produced z-stack photos and helped with the graphics. Furthermore, I wish to thank Serge Aron, Peter Boer, Barry Bolton, Pierre Charrier, Xavier Espadaler, Gerhard Heller and Bernard Kaufmann for providing samples.

\section{References}

AntWeb (2020) Version 8.37. California Academy of Science, online at https://www.antweb.org [Accessed 15 March 2020]

Boer P (2008) Plagiolepis obscuriscapa Santschi, 1923, a junior synonym of Plagiolepis pygmaea (Latreille, 1798) and the use of pigmentation as a discriminating character in ant taxonomy. Zoologische Mededelingen 82: 485-488.

Burwell CJ, Nakamura A, McDougall A, Neldner VJ (2012) Invasive African big-headed ants, Pheidole megacephala, on coral cays of the southern Great Barrier Reef: distribution and impacts on other ants. Journal of Insect Conservation 16: 777-789. https://doi. org/10.1007/s10841-012-9463-6

Buschinger A (2012): Plagiolepis alluaudi - aktuelle Informationen aus 2012. Ameisenwiki, online at [Accessed 7 July 2020]

Charrier NP, Bonsergent C, Charrier M, Malandrin L, Kaufmann B, Gippet JMW (2020) Invasive in the North: new latitudinal record for Argentine ants in Europe. Insectes Sociaux 67: 331-335. https:// doi.org/10.1007/s00040-020-00762-9

Csősz S, Fisher BL (2015) Diagnostic survey of Malagasy Nesomyrmex species-groups and revision of hafahafa group species via morphology based cluster delimitation protocol. ZooKeys 526: 19-59. https://doi.org/10.3897/zookeys.526.6037

Kirschner P, Seifert B, Kröll J, The STEPPE Consortium, Schlick-Steiner BC, Steiner F (in preparation) Pleistocene speciation in the Eurasian steppe ant Plagiolepis taurica, Santschi, 1920 revealed by integrative taxonomy.

Le Breton J (2003) Étude des interactions entre la fourmi Wasmannia auropunctata et la myrmécofaune. Comparison d'une situation en zone d'introduction: la Nouvelle-Calédonie et d'une situation en zone d'origine: la Guyane Française. Thesis. Université de Toulouse III, Toulouse, France, 234 pp.

Radchenko AG (1989) Ants of the Plagiolepis genus of the European part of the USSR. Zoologicheskij Zhurnal 68: 153-156. [In Russian]

Radchenko AG (1996) Ants of the genus Plagiolepis Mayr (Hymenoptera, Formicidae) of central and southern Palearctic. Entomologicheskoe Obozrenie 75: 178-187. [In Russian]

Salata S, Borowiec L, Radchenko A (2018) Description of Plagiolepis perperamus, a new species from East-Mediterranean and redescription of Plagiolepis pallescens Forel, 1889 (Hymenoptera: Formicidae). Annales Zoologici (Warszawa) 68(4): 809-824. https://doi.org /10.3161/00034541ANZ2018.68.4.005

Santschi F (1920) Cinq nouvelles sur les fourmis. Bulletin de la Société Vaudoise des Sciences Naturelles 53: 163-186. [Notes]

Seifert B (2008) Removal of allometric variance improves species separation in multi-character discriminant functions when species are 
strongly allometric and exposes diagnostic characters. Myrmecological News 11: 91-105.

Seifert B (2018) The Ants of Central and North Europe. Lutra Verlagsund Vertriebsgesellschaft, Tauer, $408 \mathrm{pp}$.

Seifert B (2020) The Gene and Gene Expression (GAGE) species concept: an universal approach for all Eukaryotic organisms. - Systematic Biology. https://doi.org/10.1093/sysbio/syaa032 [Published online 16 April 2020]

Seifert B, Ritz M, Csösz S (2013) Application of Exploratory Data Analyses opens a new perspective in morphology-based alpha-taxonomy of eusocial organisms. Myrmecological News 19: 1-15.

Sharaf MR, Aldawood AS, Taylor B (2011) The Formicine ant genus Plagiolepis Mayr (Hymenoptera: Formicidae) in the Arabian Pen- insula, with description of two new species. Transactions of the American Entomological Society 137 (1+2): 203-215. https://doi. org/10.3157/061.137.0113

Smith MR (1957): A contribution to the taxonomy, distribution and biology of the vagrant ant, Plagiolepis alluaudi Emery (Hymenoptera: Formicidae). Journal of the New York Entomological Society 65: 195-198.

Thurin N, Sery N, Guimbretiere R, Aron S (2011) Colony kin structure and breeding system in the ant genus Plagiolepis. Molecular Ecology 20: 3251-3260. https://doi.org/10.1111/j.1365-294X.2011.05161.x

Wetterer JK, Espadaler X, Wetterer AL, Aguin-Pombo D, Franquinho-Aguiar AM (2007) Ants (Hymenoptera: Formicidae) of the Madeiran Archipelago. Sociobiology 49(3): 265-297. 